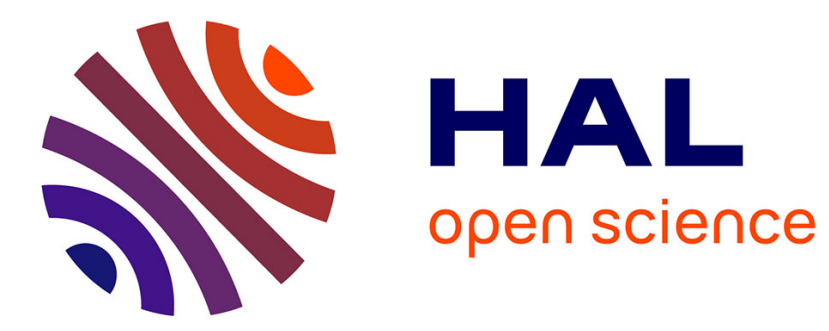

\title{
Strengthening bibliodiversity: The current situation in France at national and institutional levels
}

\author{
Jean-François Lutz, Jacques Lafait
}

\section{To cite this version:}

Jean-François Lutz, Jacques Lafait. Strengthening bibliodiversity: The current situation in France at national and institutional levels. ELPUB 2019 23rd edition of the International Conference on Electronic Publishing, Jun 2019, Marseille, France. 10.4000/proceedings.elpub.2019.15 . hal-02142296

\section{HAL Id: hal-02142296 \\ https://hal.science/hal-02142296}

Submitted on 28 May 2019

HAL is a multi-disciplinary open access archive for the deposit and dissemination of scientific research documents, whether they are published or not. The documents may come from teaching and research institutions in France or abroad, or from public or private research centers.
L'archive ouverte pluridisciplinaire HAL, est destinée au dépôt et à la diffusion de documents scientifiques de niveau recherche, publiés ou non, émanant des établissements d'enseignement et de recherche français ou étrangers, des laboratoires publics ou privés. 


\section{Strengthening bibliodiversity}

The current situation in France at national and institutional levels

Jean-François Lutz and Jacques Lafait

\section{Introduction and context}

1 Frédérique Vidal's announcement of a National Open Science Plan on the 4th of July, 2008 opened a new chapter in the way in which the opening of research, of its processes, of its results and of its tools would be conducted in France.

2 The National Plan is organized in three parts. The first is devoted to the generalisation of open access to scientific publications, the second to the structuring and opening up of research data and the third to the development of a sustainable European and international dynamic.

of the ten measures announced in the first axis, four are directly related to the notion of bibliodiversity:

- the creation of an open science fund,

- exploration of new business models for journals and open access books,

- the revitalization of university presses and of the publishing sector that choose open access

- the fact that the payment of publication fees should be solely reserved for contents that are fully open access.

4 If the announcement of the National Open Science Plan made it possible to formalize, in France, in an official document, the concept of bibliodiversity, the ground had already been prepared:

1. by the French Law for a Digital Republic ${ }^{1}$, developed in a collaborative and citizen-oriented manner and promulgated in October 2016. In summary, this law enshrines in its article 30 the right for authors to make available free of charge the final version of their accepted manuscript, as soon as it is published or with a maximum embargo of 6 months for STM disciplines and 12 months for HSS disciplines, provided that at least half of the research activity is financed by public funds (State, national funding agencies, European Union, etc.). Article 38 of the Law also sets out the conditions for carrying out Text and Data Mining (TDM). On this point, French law has been confirmed and amplified by the new European 
directive on copyright, ${ }^{2}$ which was adopted by the European Parliament on 26 March 2019 and should be transposed into French law in the coming months.

2. by the Jussieu Call for Open Science and Bibliodiversity, ${ }^{3}$ published in October 2017.

The Jussieu Call is aimed at scientific communities, professional associations and research institutions to promote a scientific publishing open-access model fostering bibliodiversity and innovation without involving the exclusive transfer of journal subscription monies to APC payments.

The Jussieu Call highlights eight key points in the development of open science through bibliodiversity. In particular: (i) the research evaluation system should be thoroughly reformed and adapted to the practices of scientific communication and (ii) experiments should be encouraged in writing practices (publishing associated data), refereeing (open peer-reviewing), content editorial services (beyond-pdf web publishing) and additional services (text mining).

It is called on research organizations and their libraries to secure and earmark as of now a share of their acquisition budgets to support the development of scientific publishing activities, which are genuinely open and innovative, and address the needs of the scientific community.

5 From these three texts, the ambition was announced and the course set.

6 The Committee for Open Science ${ }^{4}$ (CoSO) set up by the French Ministry of Research in 2018 was entrusted with the further reflection and implementation of the National Open Science Plan. Led by a steering committee comprising the presidents of all French research organisations and managed by the Director-General for Research and Innovation at the Ministry of Higher Education, Research and Innovation, assisted by his Open Science Advisor, the missions of this committee are:

1. To ensure the coordinated implementation with higher education and research of a national plan aimed at making all publications and research data openly available;

2. To enable the development of open science skills in the scientific community;

3. To coordinate national action in the field of open science on the European and international levels;

4. To define the principles and directions to be adopted concerning the assignment of financing from the national fund for open science and how it is used;

5. To define the principles and directions to be adopted for negotiations with the main scientific publishers;

6. To propose all actions likely to strengthen or promote the access to knowledge or research data to ministers of higher education and research and all public authorities.

7 Within this committee, a particular group was charged with working on the development of bibliodiversity.

\section{The work of the "Building Bibliodiversity" Project Group}

8 The "Building Bibliodiversity" Project Group was created within the Committee for Open Science, within the framework of the "Publications" and "International" colleges, to help implement actions in favour of bibliodiversity in the European and international context, based on the two pillar texts: the National Plan for Open Science and the Jussieu Call. 
9 It is composed of 40 people including 20 researchers, 10 librarians and 10 public publishers. As soon as it was set up in September 2018, its work programme was commissioned by current emergencies, namely: the announcement of the S Plan and the creation of the National Open Science Fund (FNSO), subjects on which it had to quickly develop recommendations. Its main task was nevertheless to develop criteria for the "open science" labeling of existing or future initiatives in terms of platforms, infrastructures and editorial content.

\section{Contribution to Plan S}

10 Plan S, launched in September 2018, is an initiative for Open Access publishing, supported by cOAlition $\mathrm{S}$, an international consortium of research funders. Plan $\mathrm{S}$ requires that, from 2020, scientific publications that result from research funded by public grants must be published in compliant Open Access journals or platforms. The French National Research Funding Agency (ANR), having joined cOAlition S, asked CoSO to produce an opinion and recommendations on the implementation of Plan S. ${ }^{5}$

11 Moreover, in response to the online consultation of cOAlition S about the Implementation Guidance on Plan S published on 27th of November 2018, the CoSO has written a short memorandum on "critical watchpoints" intended to highlight questionable points, or still unclear issues in the implementation guidance.

12 These recommendations and watchpoints aim essentially to respect and develop bibliodiversity in the solutions envisaged for the opening from 2020 of scientific publications financed by cOAlition S In that line it is recommended that:

- open access repositories become the venue of choice for the distribution of publications financed by the members of cOAlition $\mathrm{S}$.

- coAlition S members work together with learned societies and / or communities to take disciplinary specificities into account like scientific communication, editorial and publishing practices, and evaluation.

- financial support from cOAlition $\mathrm{S}$ be given to the open science infrastructures, platforms and journals.

- open availability of citation data in compliance with $\mathrm{I} 4 \mathrm{OC}$ standards ${ }^{7}$ be included in the mandatory quality criteria for journals and platforms.

\section{Contribution to the establishment of the national open science fund}

uring the presentation of the National Open Science Plan, the Minister of Research announced the creation of a National Open Science Fund to support the implementation of the National Plan. Placed under the control of the Steering Committee for Open Science, it will invest in an open publishing system that remains under the control of the scientific community, both in France and abroad. the transfer of a portion of traditional documentation expenses to open science. The operating mode of the fund is being developed at the time of writing, based on the recommendations of the project group.

It seems already assured that it will be used to finance:

- existing infrastructures; 
- innovative open science initiatives of existing or planned platforms (open archives, publishing platforms, etc.);

- the transition of scientific journals to open access within the framework of a "virtuous" economic model (as defined by the exemplarity criteria presented below);

- the development of French scientific publishing by supporting open access books.

16 A large proportion of the initiatives supported would be the subject of an annual call for projects and their funding could be spread over a few years.

FNSO investments in existing or planned international initiatives could be based on the annual certification carried out by $\mathrm{SCOSS}^{8}$ (The Global Sustainability Coalition for Open Science Services), while retaining projects that meet CoSo criteria and without closing the door to other international initiatives.

France will take advantage of this opportunity to take the initiative in the field of scientific publishing and develop innovative approaches to publishing made possible by digital technology, such as pre-prints, short manuscripts, data articles, open peer reviews, etc.

\section{Contribution to the development of exemplary criteria}

The Open Science Committee, was tasked with developing criteria to assess the degree of openness of infrastructures, platforms and editorial content (scientific journals and research monographs) working to disseminate scientific knowledge. The objective is to allow a qualitative labelling of these structures, with regard to open science, in particular with a view to guiding potential investments in their support.

A grid of 45 criteria, qualified as "exemplary criteria", has been produced. Half of these criteria apply to infrastructures and platforms mainly used for access and preservation of scientific knowledge, the other half to editorial content (mainly scientific journals and monograph collections). They concern the degree of openness of the structures that are examined in terms of what already exists or their plans for opening up. They are expressed in terms of ethics, transparency, economic model, governance and sustainability, all on three levels: essential, highly recommended and desired. An indispensable criterion must absolutely be fulfilled; a highly recommended criterion that is not fulfilled must be compensated elsewhere or be inapplicable; a desirable criterion is a plus if it is fulfilled.

21 These criteria are largely based on those established by Cameron Neylon et al. in $2015^{\circ}$ and are in line with the good practices highlighted by DOAJ ${ }^{10}$ and OASPA, ${ }^{11}$ the principles of the Fair Open Access Alliance, ${ }^{12}$ those of Go FAIR ${ }^{13}$ and finally those released in January 2019 by COAR and Sparc. ${ }^{14}$

These criteria will evolve pragmatically according to the opinions and feedback that will be transmitted as they are applied to specific situations and objects. They may also be enriched by a new category applicable to other subjects such as open science training or research data management. Finally, they will be supplemented as necessary by practical documents designed to explain how they can be applied to targeted objectives (financial support projects at national or establishment level, choice of development of new services, preparation of a comparative statement of existing services, etc.). These documents will propose a weighting of the criteria adapted to the targeted objective, with 
each criterion being adapted according to its degree of satisfaction with the structure examined.

\section{Support for bibliodiversity at the institutional level} implementation of the National Plan for Open Science. But it has also had a ripple effect or amplification effect at the level of higher education and research (HER) institutions. Universities are committed in various forms to open science and in particular in four ways, which we will now describe in detail below: the establishment of an investment fund common to several universities; support for open access journals; participatory funding for the open release of research monographs; and the reorientation of saved funds towards open science

\section{CURIF's action}

CURIF ${ }^{15}$ brings together French 18 research intensive universities. CURIF aims to develop among its members an activity in favour of open science. This is reflected in particular in participating in the CoSO's steering committee, in paying particular attention to the open component of negotiations with major scientific publishers and in the establishment of an action plan for open science.

Announced on July 3, 2018, the day before the speech of the HER Minister, the CURIF Open Science Plan ${ }^{16}$ aims first and foremost to set up an investment fund endowed with $€ 800,000$ with the aim of "financing projects contributing to Open Science (Hyper articles online-HAL), as well as projects for alternative open editions." At the time of writing, the progress of the fund's implementation and CURIF's investment choices are not known.

The CURIF plan includes other important aspects (training of doctoral students, reform of the evaluation of researchers...) which all show the political awareness of the current need to move towards an opening of science.

\section{Journals incubators}

Support from universities and research structures for the transition to open access dissemination of institution-supported journals has taken on a new dimension over the past year.

In France, Revues.org, now OpenEdition Journals, ${ }^{17}$ has played a structuring and driving role in enabling French HSS journals to migrate to digital format and, if possible, to open access. In parallel, some institutions wished to offer their research communities support for the open access dissemination of their scientific journals. These could be either STM journals (disciplinary fields not covered by Revues.org), or new journals that did not yet have a number of issues allowing them to apply to the Revues.org platform. Indeed, in order to better manage the flow of journal applications and to guarantee a certain robustness of journals, OpenEdition Journals requires that each candidate journal has at least two years of existence.

The University of Nice with its Revel service ${ }^{18}$ launched in 2004 was a pioneer in this field and remained alone for several years. Several other institutions have now decided to 
offer a similar hosting and support service for scientific journals: Bordeaux ${ }^{19}$, ClermontFerrand, ${ }^{20}$ Lyon $3,{ }^{21} \mathrm{MSH}$ de Dijon, ${ }^{22}$ etc. Each situation is specific (existence or not of university presses, preparation or not for a transition to a national or international platform...) but in each of the examples mentioned we observe an important role played by the documentary services (university library most often) in connection with the IT services and the scientific management of research within the institution.

All these initiatives were coordinated in 2018 in the form of an association of 12 scientific journal incubators called "Repères". Officially launched on the 20th of December 2018, ${ }^{23}$ this network of incubators aims to provide concrete answers to the needs of journal managers in HSS and STM: publication hosting, referencing, data structuring and interoperability, editorial support, transition to open access for subscription-based journals, etc. "The press release issued on this occasion emphasizes the synergies that the incubators' network wants to establish with national policies and infrastructures in order to have a coherent approach to the issue." Determined to accompany the profound changes in the landscape of scientific publications and to promote bibliodiversity, the members of the network undertake, moreover, to draft a charter of good practices, in accordance with the editorial and ethical requirements promoted by the National Open Science Plan and Plan S. Pursuing a logic of synergy, they also undertake to collaborate closely with the other networks and national actors in public scientific publishing (InSHS, Médici, OpenEdition, Métopes...) who were invited to this first working day.

\section{Participatory financing.}

31 The old principle of financing a book by subscription has become more relevant in recent years. However, one notable difference should be highlighted: it is no longer just a question of financing the production of the book by covering the costs of publication but also of ensuring that the electronic version of the book is distributed in open access.

Participatory funding for open access research books has been particularly highlighted in past years by Knowledge Unlatched (KU), which acts as an intermediary between publishers wishing to join this scheme and the university libraries that contribute to the funding. Launched in 2012 by a first call for contributions, KU's campaigns have had very little impact in France, with only one institution participating (Universite de Lorraine). In addition to the relative novelty of such a project, it is clearly the language of the works funded that has been a major obstacle to greater involvement by French universities.

This is why OpenEdition Books approached the Couperin consortium in 2015 to consider a mechanism that would enable French institutions to promote the emergence of open access research monographs. After several exchanges, OpenEdition partnered with Knowledge Unlatched to implement a pilot project that was launched in 2018 under the name "OpenEdition Books Select 2018." ${ }^{24}$ A group of about twenty international librarians, including about ten French librarians, participated in the selection of the 30 books to be financed among all those proposed by the partner publishers. Of these books, 10 were new and 20 were background books. The campaign received a very positive response from French institutions. With a contribution set at $1200 €, 39$ French universities and organisations have so far committed themselves (out of a total of 59), ${ }^{25}$ which has enabled the release of 6 new books. ${ }^{26}$

Although relatively modest, these beginnings are very promising because they show that French universities are able to mobilize to finance initiatives related to open science. 
Several universities have expressed a desire to publicly show their support like the Condorcet Campus ${ }^{27}$ and the testimonies of librarians ${ }^{28}$ on the reasons for supporting this project are convergent. As a librarian at the University of Strasbourg points out: "For us, this means concretely encouraging an alternative and innovative model of scientific publication through the upstream financing of research works in the field of the humanities and social sciences, which is also in French, in order to enable them to be distributed in open access. In this way, we are actively involved in the dynamics of the Jussieu Call for Open Science and Bibliodiversity, which was signed by Unistra, as well as in the National Plan for Open Science."

It should be stressed, however, that the hardest work remains to be done. This consists first of all in amplifying the cultural change within libraries so that this type of "documentary buying" is fully and widely integrated by the teams and not only reserved for open science officers. Secondly, to use a rugbistic metaphor, the try must be transformed and the pilot campaign must be followed by larger-scale operations with a transformative impact.

\section{Reorientation of savings.}

The renewal of the contract between the French HER institutions and the scientific publisher Springer gave rise to rather complex negotiations, which led to the unsubscription of several intensive research universities. Some of them clearly indicated that the money saved would be redirected to open publishing initiatives.

37 This is the case of the University of Lorraine, which stated in a press release issued in April $2018^{29}$ that "it decided in 2018 to allocate part of the funds generated by the Springer cancellation to financial support, in a spirit of partnership, for several publishing initiatives that meet the principles of scientific quality, openness, transparency and governance focused on academic communities". This choice was made in a situation where the subscription model for journals packages coupled with a continuous price increase makes it impossible to continue with the current system. This need for systemic change begins with relatively modest support for initiatives in a variety of disciplinary fields: Fair Open Access Alliance, SciPost, EDP Sciences, OpenEdition, Erudit, Epiga magazine, Open Library of Humanities.

38 A similar process has taken place at the University of Rennes $1,{ }^{30}$ which has also been involved in supporting several open science initiatives

\section{Challenges and perspectives}

The development of bibliodiversity is not an objective that a country can achieve on its own, through its central structures or its HER institutions. The international dimension of scientific research, the systemic aspect of scientific communication processes, requires us to look beyond France's borders both to draw inspiration from the examples of other countries and also and above all to coordinate actions carried out at the international level.

40 The Coso's work has from the outset integrated this dimension and, with regard to bibliodiversity and the financing of open science, privileged contacts were established during 2018-2019 with the SCOSS project, ${ }^{31}$ which aims to finance open science 
infrastructures. Discussions are still ongoing on how CoSO's support for SCOSS could be realised, but it is clear that this is an exemplary initiative and responds to a need to stabilise the ecosystem of open scientific communication.

Beyond the question of shared investments at the international level, question arises of the convergence of strategies between different countries to finance free access to scientific publications. On this point, the approach put forward by the Max-Planck Gesellschaft and named OA2020 aims to make a transition to open access by negotiating at the national level so-called transformative agreements through which the publications of researchers affiliated to a research structure in this country would be distributed in free access on the publisher's website. Proposed in 2016, the OA2020 initiative has since then received increasing support both from several countries (Sweden, Germany, Norway) and prestigious institutions (University of California). However, in its initial design, OA2020 presented the risk of changing only financial flows (from subscription big deals to APC big deals) without allowing a transformation of the ecosystem and the emergence of new players. The OA2020 approach seems to have evolved over the years, which led to the publication in December 2018 of a joint text with the Jussieu Call ${ }^{32}$ calling for the financing of bibliodiversity with a realistic objective of a relative medium-term balance between subscription-based content, open content funded by APCs and content for which no publication fees would be charged.

It remains to be seen how this call for greater coordination can be translated into concrete action. Initial contacts show that, while the objective is shared, discussions are still necessary to reach a shared vision between the various actors on the means to implemented and to achieve it.

\section{NOTES}

1.

https://www.legifrance.gouv.fr/affichTexte.do?

cidTexte $=$ LEGITEXT000033205014 \&dateTexte $=20190527$

2. http://www.europarl.europa.eu/doceo/document/TA-8-2019-0231_EN.html

3. https://jussieucall.org/jussieu-call/

4. https://www.ouvrirlascience.fr/the-committee-for-open-science/

5. https://www.ouvrirlascience.fr/plan-s-recommendations/

6. https://www.ouvrirlascience.fr/critical-watchpoints-about-plan-s-implementation-guidancea-contribution-of-the-open-science-committee/

7. https://i4oc.org/

8. https://sparceurope.org/scoss/

9. https://cameronneylon.net/blog/principles-for-open-scholarly-infrastructures/

10. https://doaj.org/publishers

11. https://oaspa.org/principles-of-transparency-and-best-practice-in-scholarly-publishing-3/

12. https://www.fairopenaccess.org/

13. https://www.go-fair.org/fair-principles/

14. https://www.coar-repositories.org/files/COAR-SPARC-Good-Practice-Principles.pdf

15. http://www.curif.org/en/1408-2/who-we-are/ 
16. http://www.curif.org/fr/la-curif-sengage-pour-la-science-ouverte/

17. https://journals.openedition.org/?lang=en

18. http://revel.unice.fr/

19. http://open.u-bordeaux.fr/journals/

20. https://polen.msh.uca.fr/

21. https://revues.univ-lyon3.fr/

22. https://preo.u-bourgogne.fr/portail/

23. http://bu.univ-lyon3.fr/medias/fichier/communique-lancement-reseau-reperesvf_1545301328984-pdf?ID_FICHE=201634\&amp;INLINE=FALSE

24. https://leo.hypotheses.org/13771

25. https://www.openedition.org/22515

26. https://oep.hypotheses.org/2181

27. https://www.campus-condorcet.fr/Actualites/OpenEdition-Books-Select-le-CampusCondorcet-affirme-son-

28. https://oep.hypotheses.org/2204

29. http://factuel.univ-lorraine.fr/node/8472

30. https://www.univ-rennes1.fr/actualites/27032018/lopen-access-luniversite-de-rennes-1

31. http://scoss.org/

32. https://www.ouvrirlascience.fr/building-bibliodiversity-with-multiple-approaches-jointstatement-of-the-french-open-science-committee-promotors-of-the-jussieu-call-and-the-openaccess-2020-initiative/

\section{ABSTRACT}

Almost one year after the announcement of the French National Plan for Open Science, the intervention aims at presenting a progress report on achievements in strengthening bibliodiversity and setting up a National Open Science Fund, two of the objectives of the Plan.

At the national level, the work was carried out within a working group the Open Science Committee. Four complementary aspects were taken into account:

- the establishment of exemplary criteria to assess infrastructures and platforms in terms of governance, ethics, openness and sustainability. These 40 criteria are to be used in the evaluation of the initiatives that will apply to the National Open Science Fund.

- support for the strategic orientation of the National Open Science Fund.

- the drafting of recommendations for the implementation of Plan S by the Agence Nationale de la Recherche (ANR), which is member of cOAlition S.

- information exchange and coordination with other initiatives such as OA2020 and SCOSS.

At the institutional level, several initiatives have made it possible to initiate greater financial support for open science. Four case studies illustrate this fact:

- the launch of an open science fund with a $800 \mathrm{~K} €$ budget by the 18 French major research universities (Curif),

- the establishment of a network of open access journals incubators run by 12 institutions (Repères),

- the support of 43 French libraries for the first campaign aiming at funding open access monographs in French 
- the reallocation of part of the savings due to the non-renewal of the subscription to the Springer journals package by the universities of Lorraine and Rennes-1.

INDEX

Keywords: Open access, open science, bibliodiversity, academic publishing, France

\section{AUTHORS}

JEAN-FRANÇOIS LUTZ

Université de Lorraine, France

lutz5@univ-lorraine.fr

\section{JACQUES LAFAIT}

Sorbonne Université, France 